Fourth International Conference on Sustainable Construction Materials and Technologies http://www.claisse.info/Proceedings.htm

SCMT4

Las Vegas, USA, August 7-11, 2016

\title{
Investigation of Early Geopolymerization Process of Fly Ash-Based Geopolymer Paste Using Acoustic Emission Technique
}

\author{
Lateef N. Assi ${ }^{1 a}$, Rafal Anay ${ }^{1 b}$, Davis Leaphart ${ }^{2}$, Vafa Soltangharaei ${ }^{3 a}$, and Paul Ziehl ${ }^{3 b}$ \\ ${ }^{1}$ Research Assistant, University of South Carolina, Dept. of Civil and Environ. Engineering, 300 Main \\ Street, B127, Columbia, SC 29208, USA, \\ ${ }^{1 a}$ Email : $<$ lassi@email.sc.edu>, ${ }^{1 b}$ Email $:<$ ranay@email.sc.edu>. \\ ${ }^{2} 100$ Maple Shade Ln, Lexington, SC 29037, USA, ${ }^{2}$ Email: <davismleaphart@gmail.com>. \\ ${ }^{3}$ Research Assistant: University of South Carolina, Dept. of Civil and Environ. Engineering, 300 Main \\ Street, ${ }^{3 a}$ B127, ${ }^{3 b}$ C206, Columbia, SC 29208, USA, \\ ${ }^{3 a}$ Email : $<$ lassi@email.sc.edu>, ${ }^{3 b}$ Email: <ziehl@cec.sc.edu>.
}

\begin{abstract}
Development of sustainable construction materials has been the focus of research efforts worldwide in recent years. Concrete is a major construction material; hence, finding alternatives to ordinary Portland cement is of extreme importance due to the high levels of carbon dioxide emissions associated with its manufacturing process. This study investigates the geopolymerization process, monitored using a data acquisition system. Two different water/binder weight ratios, 0.30 and 0.35 respectively, were monitored using acoustic emission. Results show that there is significant difference in the acquisition data between the two different water/binder weight ratios. In addition, acoustic emission may be used to beneficially monitor and investigate the early geopolymerization process.
\end{abstract}

\section{INTRODUCTION}

Due to the global concern about $\mathrm{CO}_{2}$ emissions nowadays, it is well accepted that a new kind of cement is in need to replace Portland cement with improved environmental, mechanical, and durability performance. Portland cement is responsible for $7 \%$ of total $\mathrm{CO}_{2}$ [Chen et al; 2010] because every ton of Portland cement releases roughly one ton of $\mathrm{CO}_{2}$ emissions [Hasanbeigi et al; 2010] due to the high energy required for production. Alkali activated geopolymer cement is one potential alternative to Portland cement. It may help to address the mentioned problem once the mechanical and chemical behaviors are understood.

Alkali activated cement (geopolymer cement) is an inorganic polymer, produced by reacting a source of aluminate silicate, such as fly ash, slag, or metakaolin, with an activating solution. For example, either the common activating solution: sodium silicate, sodium hydroxide and water: or the alternative activating solution: sodium hydroxide, silica fume and water. Several researchers [Wallah et al 2000; Hardjito et al 2003; Sumajouw et al 2007; Wallah et al 2011; and Assi et al 2016] have shown that alkali activated concrete has enhanced mechanical properties. For instance, this material demonstrates high early and final 
compressive strength, low sulfate attack, resistance against acid erosion, and better performance under high temperatures when it compared with conventional Portland cement concrete. However, the geopolymerization process is still ambiguous and needs to be identified to better understand, and then enhance, the chemical, microstructural, and mechanical properties.

Acoustic emission has been used to monitor chemical phenomena in both structural and material science due to its high sensitivity. More specifically, acoustic emission has been utilized to monitor the early hydration process of different types of cement such as calcium aluminate in paste samples [Chotarda et al; 2003a, 2003b, 2005]. Results of acoustic emission were characterized, and assigned to hydration mechanisms and compared to x-ray tomography. In addition, acoustic emission data were compared to the measured temperature of cement paste samples (Pazadera et al 2014). Acoustic emission integrity in describing early hydration of Portland cement was assessed (Sayers and Dahlin 1993; Wu et al 2000 and Van Den Abeele et al 2009), and the acoustic emission techniques were proven sensitive enough to monitor chemical and synthetic processes, as well as microcrack initiation.

Geopolymerization is a reaction producing silico-aluminates. For instance, any source of pozzolanic materials, such as fly ash or slag. Pozzolanic materials have high aluminate and silica portion, which is ready to dissolve in an alkaline solution, will lend itself to geopolymerization (Khale and Chaudhary 2007). Several researchers have attempted to explain the geopolymerization process and its related mechanism. Fernandez- Jimenez and Palomo investigated several factors including the amount of reactive silica, particle size distribution, and the vitreous phase content (Fernandez-Jimenez and Palomo 2003). It was found that silica plays a dominant role in the chemical reaction and that the aluminosilicate gel is the main responsible party for mechanical properties (Palomo et al 1999). Jaarsveld and Deventer explained the mechanism of geopolymerization according to Purdon; by liberation of silica, alumina and lime in presence of an activating solution, and then formation of aluminate-silicate hydrate. Generally, the geopolymerization mechanism can be summarized into dissolution of aluminate and silicates oxides due to hydroxide ions, orientation of dissolved products, and finally condensation and hardening [Khale and Chaudhary 2007]. Condensed products have poor ordered structures (amorphous structure) due to the rapidness of the reaction (Palomo et al 1999). However, most of researches have not assigned the mechanisms stages in regard to the time and temperature throughout geopolymerization process.

In this paper, two of the fly ash-based geopolyemer pastes with water/binder weight ratios, 0.3 and 0.35 , were monitored. The activating solution used was a mixture of silica fume, sodium hydroxide and water. Acoustic emission sensors were used to monitor the early geopolymerization process for 72 hours with an AEwin data acquisition system. The data was post-processed with AEwin.

\section{MATERIALS AND METHODS}

In this section, two different water/binder (sodium hydroxide, silica fume, and fly ash) weight ratios were chosen, 0.30 and 0.35 respectively. The reason for choosing these water/binder ratios is due to the fact that for a lower water/binder weight ratio of 0.27 , the initial time setting is rapid (less than three minutes), however, for a higher water/binder weight ratio of 0.45 , the initial time setting did not occur.

The materials used for fabrication of the fly ash-based geopolymer paste included fly ash (ASTM class F) and activating solution (sodium hydroxide mixed with silica fume). The fly ash was sourced from Wateree Station in South Carolina. The Wateree Station fly ash was subjected to a proprietary carbon burn out process. Chemical compositions of the fly ash source are shown in Table 1. The activating solution used was silica fume (Sikacrete 950DP, densified powder silica fume), sodium hydroxide (97-98 purity, DudaDiesel), and water. The mixture proportions of the fly ash-based geopolymer paste are provided in Table 2. 


\section{Table 1. XRF chemical analysis of fly ash}

\begin{tabular}{|c|c|}
\hline Chemical analysis & Wateree Station wt.\% \\
\hline Silicon Dioxide & 53.5 \\
\hline Aluminum Oxide & 28.8 \\
\hline Iron Oxide & 7.47 \\
\hline Sum of Silicon Dioxide, Aluminum Oxide & 89.8 \\
\hline Calcium Oxide & 1.55 \\
\hline Magnesium Oxide & 0.81 \\
\hline Sulfur Trioxide & 0.14 \\
\hline Loss on Ignition & 3.11 \\
\hline Moisture Content & 0.09 \\
\hline Total Chlorides & ----- \\
\hline Available Alkalies as $\mathrm{NaO}_{2}$ & 0.77 \\
\hline
\end{tabular}

Table 2. Mixture proportions

\begin{tabular}{|c|c|c|c|c|c|}
\hline $\begin{array}{c}\text { Fly ash-based geopolymer paste } \\
\text { (water/binder*) }\end{array}$ & $\begin{array}{c}\text { Fly ash, } \\
\mathrm{kg} / \mathrm{m}^{3} \\
\left(\mathrm{lb} / \mathrm{ft}^{3}\right)\end{array}$ & $\begin{array}{c}\text { Water, } \\
\mathrm{kg} / \mathrm{m}^{3} \\
\left(\mathrm{lb} / \mathrm{ft}^{3}\right)\end{array}$ & $\begin{array}{c}\mathrm{w} / \mathrm{b} * \\
\text { ratio }\end{array}$ & $\begin{array}{c}\text { Sodium } \\
\text { hydroxide, } \\
\mathrm{kg} / \mathrm{m}^{3} \\
\left(\mathrm{lb} / \mathrm{ft}^{3}\right)\end{array}$ & $\begin{array}{c}\text { Silica fume, } \\
\mathrm{kg} / \mathrm{m}^{3} \\
\left(\mathrm{lb} / \mathrm{ft}^{3}\right)\end{array}$ \\
\hline $\begin{array}{c}\text { Mix 1: } \\
\begin{array}{c}\text { silica fume based activating } \\
\text { solution paste }(0.30)\end{array}\end{array}$ & $474(29.6)$ & $175(10.9)$ & 0.30 & $\begin{array}{c}61.6 \\
(3.81)\end{array}$ & $46.2(2.92)$ \\
\hline $\begin{array}{c}\text { Mix 2: } \\
\text { silica fume based activating } \\
\text { solution paste }(0.35)\end{array}$ & $474(29.6)$ & $204(12.7)$ & 0.35 & $\begin{array}{c}61.6 \\
(3.81)\end{array}$ & $46.2(2.92)$ \\
\hline
\end{tabular}

*Binder (b) = combined weight of the fly ash, sodium hydroxide, and silica fume.

\section{ACTIVATING SOLUTIONS}

The silica fume based activating solution was a mixture of sodium hydroxide flakes dissolved in water, along with silica fume powder. Following the addition of silica fume powder, the entire mixture was stirred for two minutes. The mixing of silica fume with sodium hydroxide and water was an exothermic process (in excess of $80^{\circ} \mathrm{C}\left[176^{\circ} \mathrm{F}\right]$ ). The activating solution was kept in a closed container in an oven at $75^{\circ} \mathrm{C}$ $\left(167^{\circ} \mathrm{F}\right)$ for roughly 12 hours to assure that the sodium hydroxide flakes and silica fume powder were completely dissolved. The water/binder ratio was calculated at $30 \%$ and $35 \%$. This ratio was calculated by dividing the water weight over summation of dried fly ash, sodium hydroxide and silica fume weight. The activating solution was mixed with the fly ash for three minutes manually, and then each water/ binder ratio was cast in two $3.8 \mathrm{~cm} \mathrm{X} 3.8 \mathrm{~cm} \mathrm{X} 11.4 \mathrm{~cm}$ (1.5 in X1.5 in X4.5 in) plastic molds. The plastic molds were vibrated for ten seconds, thermocouples were inserted inside the samples, and the acoustic emission sensors were attached. The mixing procedure described above is the same as described in Assi et al; 2016 (Assi et al 2016).

\section{EXPERIMENTAL TEST SETUP}

The acoustic emission system used in this investigation consisted of a Digital SPARTAN (DiSP) data acquisition system, 16 channel bench top acoustic emission system containing PCI/DSP-4 cards. The setup 
is ideal for research and applications where high speed, low noise, varied testing purposes are required. WDI-automated sensors, broadband acoustic emission sensors, (40 dB integral preamplifier) $200-900 \mathrm{kHz}$ frequency range, were used to monitor and collect acoustic emission data (acoustic emission AEwin 2004). A background noise test was conducted in the material laboratory at the University of South Carolina to identify the threshold prior the actual test. As a result of this step, the threshold was set to $31 \mathrm{~dB}$. During the hydration test, all of the four specimens were kept inside a plastic chamber with the ambient temperature of $22 \pm 3^{\circ} \mathrm{C}$. In order to isolate the specimens from outside vibrations, low-density foam pad was placed on the floor of the plastic chamber (Lura et al 2009). Five acoustic emission broadband sensors (WDI-AST) with frequency range of $200-900 \mathrm{kHz}$, were used in each test; four of them were attached on the top of the specimens, two for each water/binder ratio specimens, and the fifth sensor was attached on a plastic piece as a control sensor as shown in Figure 1. As a couplant between the acoustic emission sensors and the acetate sheets, Dow high vacuum grease was used. Temperature and humidity data logger was used to monitor the humidity and temperature inside the plastic chamber. Each test was conducted for 72 hours.

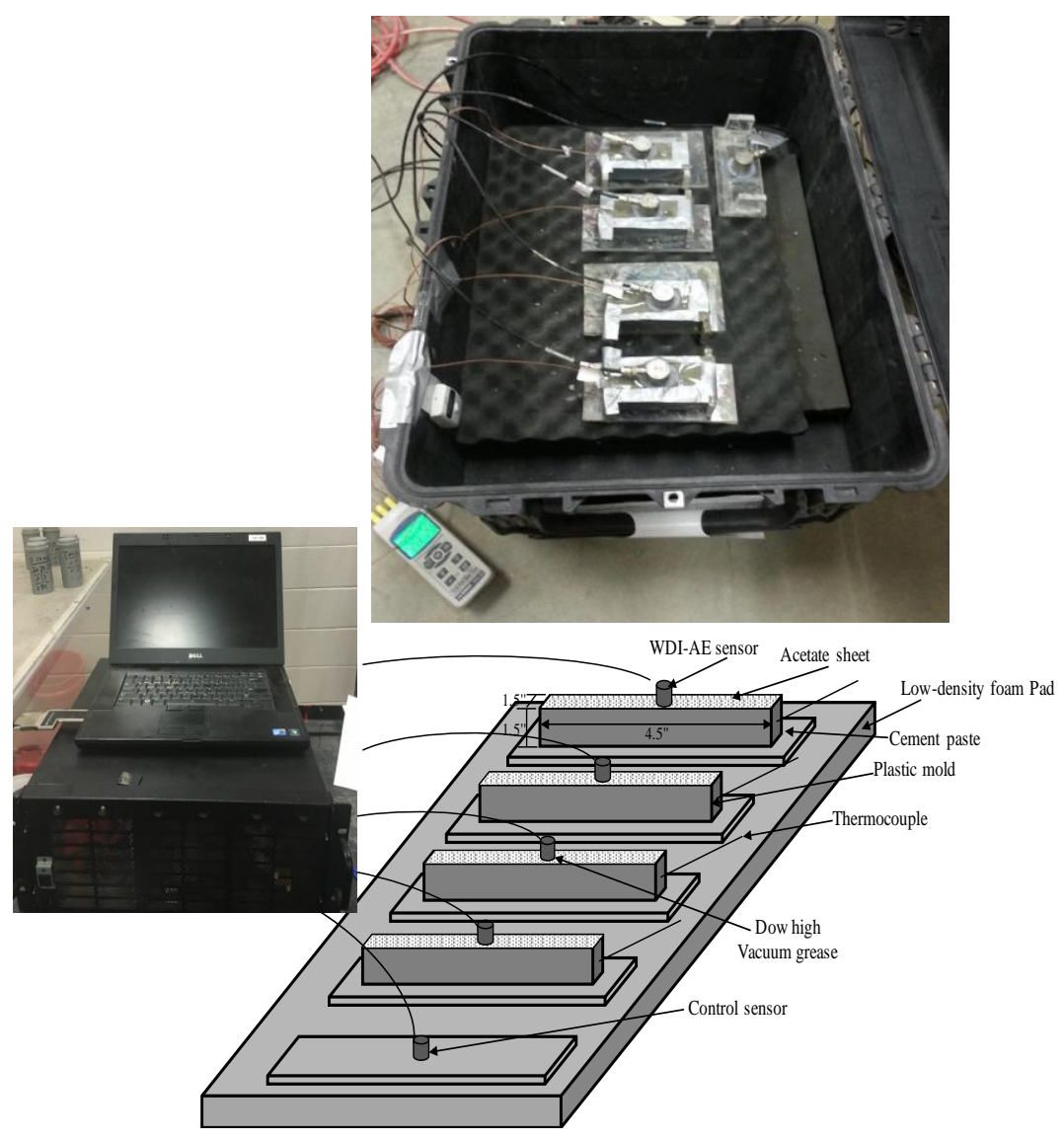

Figure 1. Experimental test setup, a: Scheme, b: Photograph of real test

\section{RESULTS AND DISCUSSION}

Geopolymerization is referred to a chemical reaction that involves occurring silico-aluminates [ Khale and Chaudhary 2007]. It takes place when an activating solution such as mixture of silica fume, sodium hydroxide and water, mixed with aluminate- silicate source such as fly ash. The geopolymerization process can be summarized by a) dissolution, with formation of mobile precursors through action of hydroxide ions, b) partial orientation of mobile precursors and c) precipitation where whole the system hardens into an 
inorganic polymeric structure. External heat and alkali content plays strong role in the geopolymerization process (H.J.H. Brouwers and R.J. Van Eijk; 2003). For instance, if external heat and ph concentration increase, geopolymerization process will become rapid comparison with hydration of conventional cement. Due to rapid reaction, the geopolymerization products' structure is amorphous. The main chemical products are composed of silicon and aluminum. The three dimensional structure of amorphous product consists of poly (sialate) type ( $\mathrm{Si}-\mathrm{O}-\mathrm{Al}-\mathrm{O}-$ ), the poly (sialate-siloxo) type ( $\mathrm{Si}-\mathrm{O}-\mathrm{Al}-\mathrm{O}-\mathrm{Si}-\mathrm{O}-)$, and the poly(sialatedisiloxo) type (Si-O-Al-O-Si-O-Si-O-) (Davitovis; 1994). The geopolymerization process can be summarized schematically as follows:

$$
\begin{aligned}
& n\left(\mathrm{Si}_{2} \mathrm{O}_{5}, \mathrm{Al}_{2} \mathrm{O}_{2}\right)+2 n \mathrm{NiO}_{2}+4 n \mathrm{H}_{2} \mathrm{O} \stackrel{\mathrm{NaOH}, \mathrm{KOH}}{\longrightarrow} n(\mathrm{OH})_{3}-\mathrm{Si}-\mathrm{O}-\stackrel{(-)}{\mathrm{Al}}-\mathrm{O}-\mathrm{Si}-(\mathrm{OH})_{3}
\end{aligned}
$$

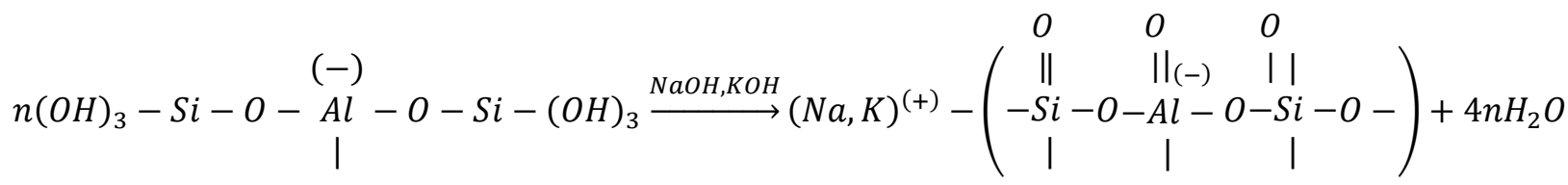

(Davitovis; 1994)

\section{RELATIONSHIP BETWEEN ACOUSTIC EMISSION HITS AND TEMPERATURE HISTORY}

The maximum temperatures which are $36^{\circ} \mathrm{C}$ and $30^{\circ} \mathrm{C}$ for fly ash -based geopolymerization in the Figure 3 , are observed at 0.13 and 0.40 hours after starting of the tests, for water/binder weight ratios of 0.30 and 0.35 , respectively. Furthermore, the temperature increase in the accelerated rate region, was $9.40{ }^{\circ} \mathrm{C}$ and $4.90{ }^{\circ} \mathrm{C}$ for samples with water/binder weight ratios of 0.30 and 0.35 , respectively. These observations show that fly ash-based geopolymer paste with lower water/binder weight ratio, geopolymerizes sooner and releases more heat compared to the sample with larger water/binder weight ratio. In addition, by comparing the maximum internal temperature for the conventional Portland cement paste to fly ash-based geopolymer paste, the heat of hydration process tends to be higher than geopolymerization process. This may be considered an advantage for fly ash-based geopolymer paste because lower internal heat will reduce potential microcrack initiation.

In addition, by looking for the temperature acceleration curve part in Figure 3, the acoustic emission amplitude data is intense compared with the rest of the temperature curve. There are some related mechanisms can be assigned to describe the temperature rise and the acoustic emission data. Aa explained in the discussion part, the first stage of geopolymerization process is the dissolution and mobile precursors due to presence of hydroxide ions. Usually, during this process, the internal heat starts to increase due to the material dissolving. The second stage of geopolymerization process is partial orientation of mobile precursors. These two stages were attributed that they occurred at $0.13 \mathrm{hrs}$ and $0.40 \mathrm{hrs}$ for w/binder weight ratio 0.30 and 0.35 sequentially. As described in the introduction, the early geopolymerization process is rapid, especially the stage one and two. The acoustic emission analyses have confirmed these hypotheses. The third stage of the geopolymerization process is the hardening into an inorganic polymeric structure. This stage is assigned to the third part of the the temperature curve which is the deceleration part. At this stage, the reaction process starts to be slow, in absence of external heat, in the geopolymer cement. The acoustic emission data as shown in Figure 3, was assigned to the forming microcracks as well as slow geopolymerization reaction activity. 


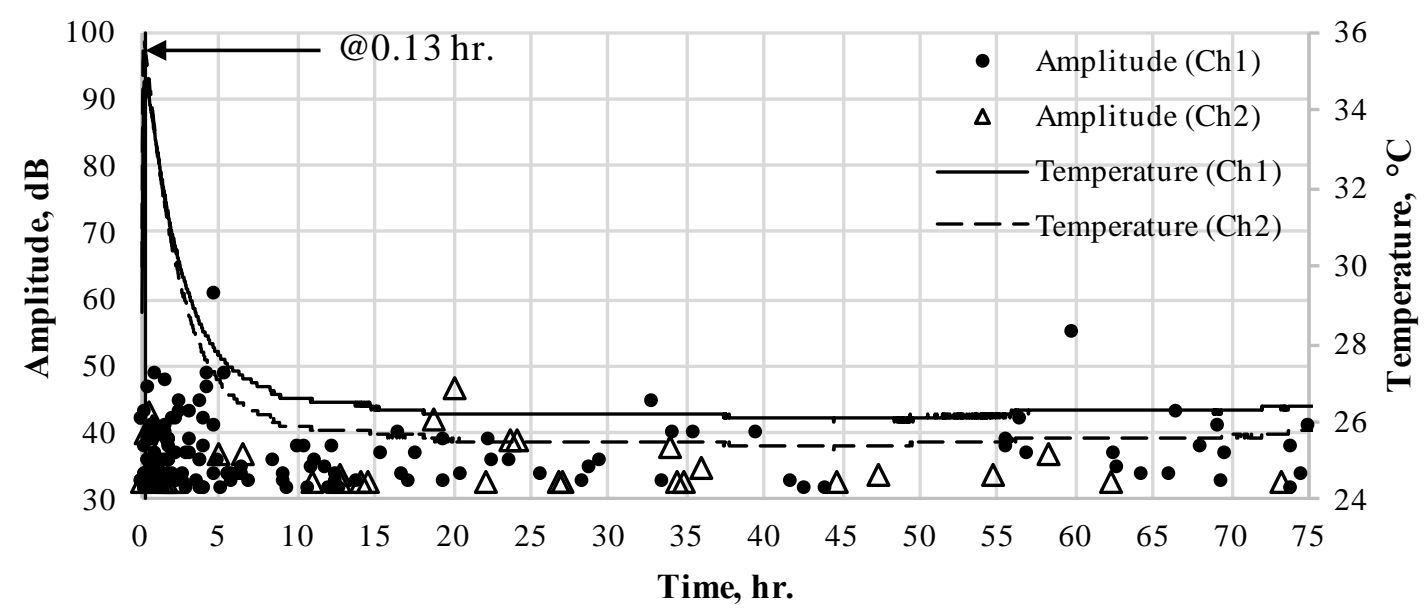

a) Water/binder ratio $=30 \%$

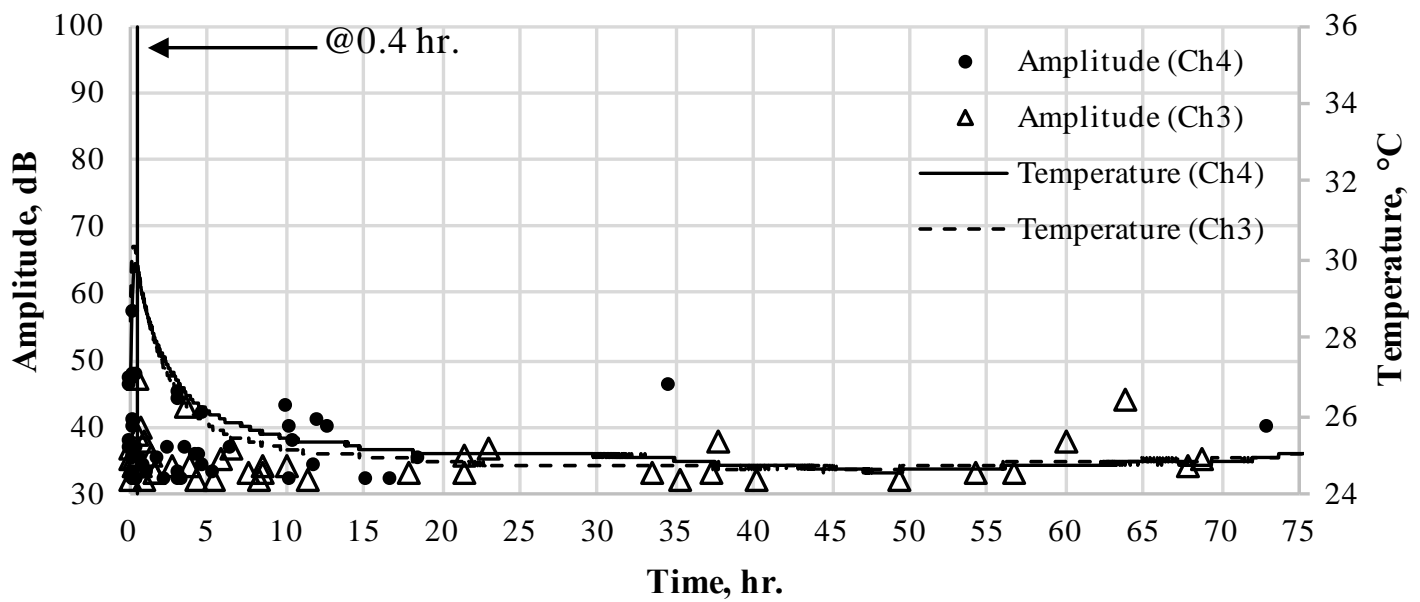

b) Water/binder ratio $=35 \%$

Figure 3. Amplitude of acoustic emission signals and temperature distribution during geopolymerization process

As shown in the Figures 3 and 4, the acoustic emission signals near the maximum temperature have higher amplitude, duration, while signal strength of the signals in the beginning of the acceleration and entire of deceleration regions is mostly smaller. This phenomenon depicts the correlation between acoustic emission hits and geopolymerization process, showing that acoustic emission method has a robust potential for detecting early geopolymerization activities in a geopolymer paste. 


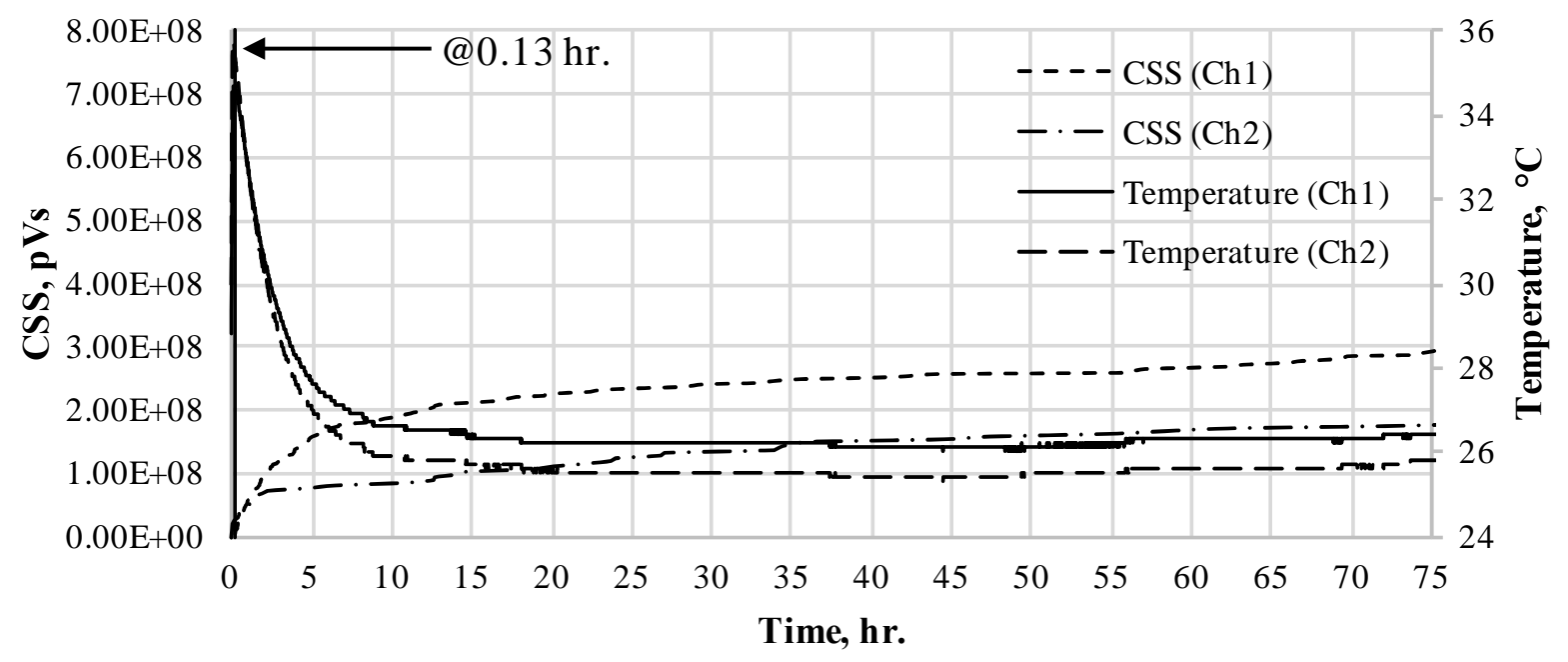

a) Water/binder ratio $=30 \%$

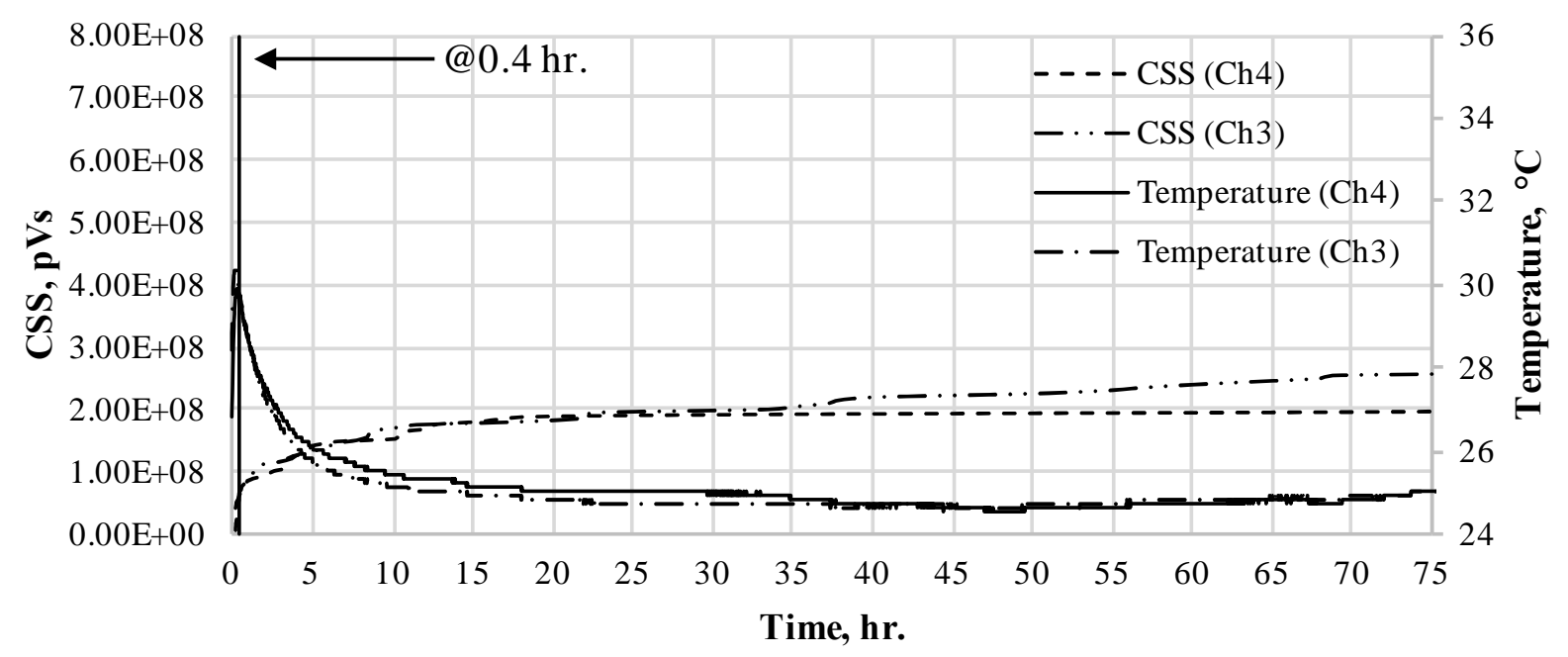

b) Water/binder ratio $=35 \%$

Figure 4. Cumulative signal strength and temperature distribution during geopolymerization process 


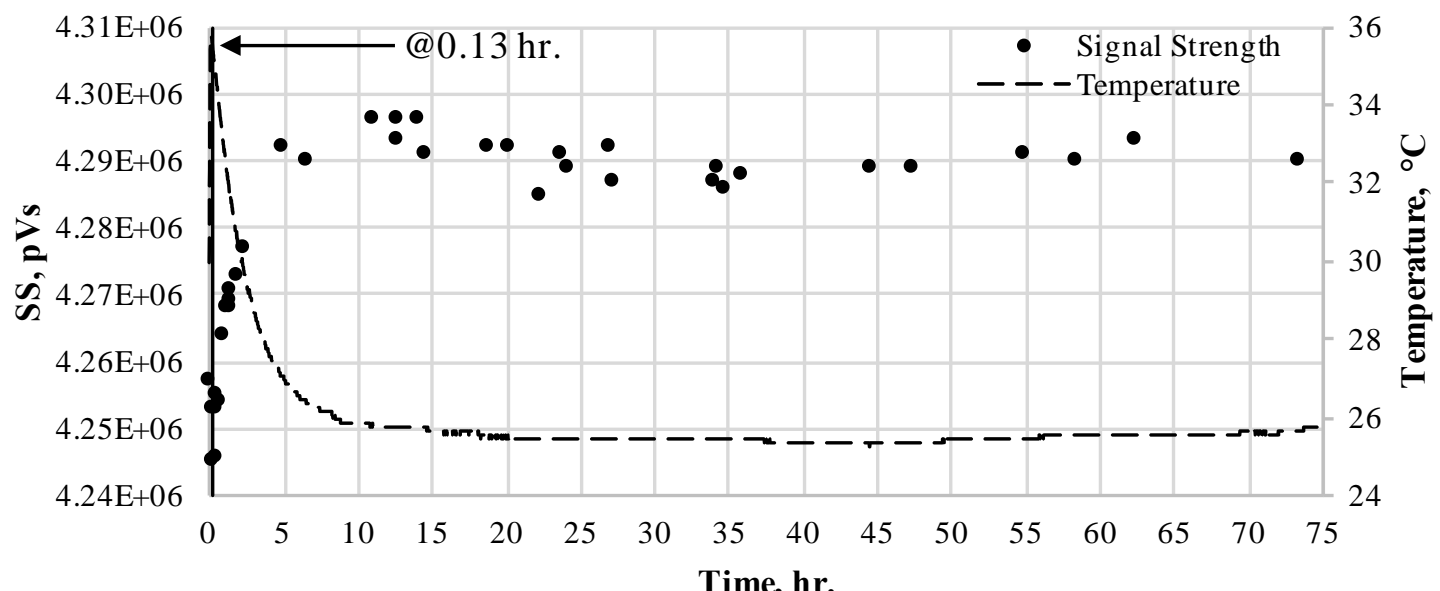

Time, hr.

a) Water/binder weight ratio $=30 \%$

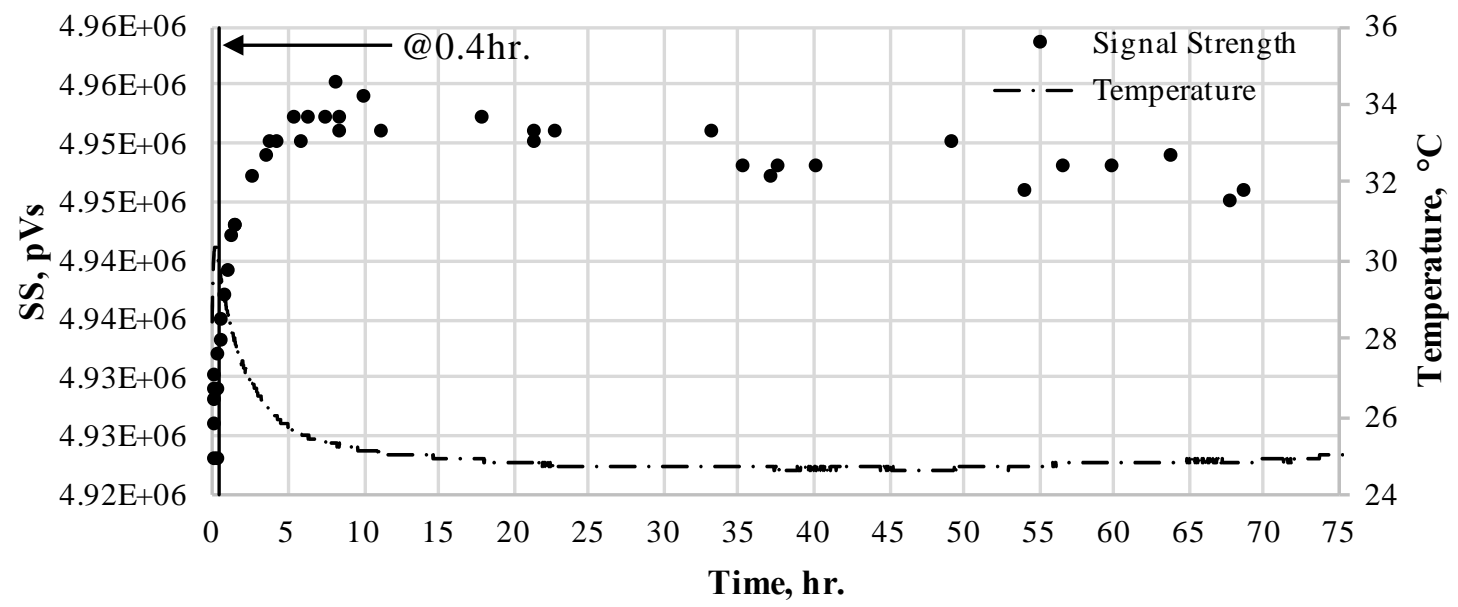

b) Water/binder weight ratio $=35 \%$

Figure 5. Signal strength and temperature distribution during hydration process

As shown in Figure 4, the increase in CSS rate begins to occur in the accelerated region prior to the temperature peak, and extends a few hours after the temperature peak. The first signal of the 0.30 and 0.35 water/binder weight ratio samples was recorded in the early stage of geopolymerization process at 0.10 hours after test onset. Occurrence of the first hit at the beginning stage of the acceleration period shows that the acoustic emission method is capable to recording the signals due to activities at the start of the accelerated period, despite the low energy of activities in that region. In addition, as shown in the Figure 5, there are a significant similarity in the signal strength in 0.30 and 0.35 water/binder weight ratios. The signal strength acceleration continues to increase until 5 hours after the test began. The accelerating part in the signal strength is attributed to the change of the fly ash-based geopolymer concrete from liquid to solid state. 
Figure 5 shows the signal strength for both 0.30 and 0.35 water/binder weight ratio throughout 75.0 hrs respectively. The minimum signal strength started from $4.92 * 10^{-6}$ pico volts/second $(\mathrm{pVs})$ and the maximum strength is around $4.96 * 10^{-6}$ for both 0.30 and 0.35 water/binder weight ratio. The signal start with low strength, and then it gradually increased till $5 \mathrm{hrs}$ of the test onset. Thereafter, the signal strength became constant.

\section{CONCLUSION}

In this paper, acoustic emission was employed to investigate the fly ash-based geopolymerization process and to find the relationship between recorded signals and different activities and mechanisms associated to fly ash-based geopolymer paste geopolymerization. The results of this study are summarized as follows:

- Acoustic emission monitoring proved useful for monitoring early fly ash-based geopolymer paste geopolymerization activities. Duration, signal amplitude, signal strength of received signals had a correlation with hydration temperature distribution during fly ash-based geopolymer paste geopolymerization.

- The measured temperature readings indicate the geopolymerization process potential advantages in comparison with conventional cement.

- Acoustic emission activity may be utilized to assess the speed of the geopolymerization process.

- Rapid increase in the signal strength may be attributed to the change from the liquid to solid state of the fly ash-based geopolymer paste samples.

More work should be done to analyze and characterize the wave forms and frequencies of the acoustic emission data.

\section{ACKNOWLEDGEMENT}

This research is based upon work supported partially by the U.S. Department of Energy Office of Science, Office of Basic Energy Sciences, and Office of Biological and Environmental Research under Award Number DE-SC-00012530.

\section{REFERENCES}

Acoustic emission win version E4.30 (2004), Mistras Group Inc., Princeton Junction, NJ.

Van Den Abeele, K. Desadeleer, W., De Schutter, G., Wevers, M., (2009). “Active and passive monitoring of the early hydration process in concrete using linear and nonlinear acoustics." Cement and Concrete Research, 39(5), pp.426-432.

Al Bakri, A.M.M., Kamarudin, H., Bnhussain, M., Nizar, I. K., Rafiza, A. R., Izzat, A. M., (2011). "Chemical Reactions in the Geopolymerisation Process Using Fly Ash-Based Geopolymer: A Review." Journal of Applied Sciences Research, 7(7), pp.1199-1203.

Assi, L.N., Deaver, E., ElBatanouny, M. K., Ziehl, P., (2016). "Investigation of early compressive strength of fly ash-based geopolymer concrete." Construction and Building Materials, 112, pp.807-815.

Chen, C., Habert, G., Bouzidi, Y., Jullien, A., (2010). "Environmental impact of cement production: detail of the different processes and cement plant variability evaluation." Journal of Cleaner Production, 18(5), pp.478-485.

Chotard, T., Rotureau, D. \& Smith, A., (2005). "Analysis of acoustic emission signature during aluminous cement setting to characterise the mechanical behaviour of the hard material." Journal of the European Ceramic Society, 25(16), pp.3523-3531. 
Chotard, T.J., Smith, A., Rotureau, D., et al., (2003). "Acoustic emission characterisation of calcium aluminate cement hydration at an early stage." Journal of the European Ceramic Society, 23(3), pp.387398.

Chotard, T.J., Smith, A., Boncoeur, M.P., Fargeot, D., Gault, C., (2003).” Characterisation of early stage calcium aluminate cement hydration by combination of non-destructive techniques: Acoustic emission and X-ray tomography." Journal of the European Ceramic Society, 23(13), pp.2211-2223.

Davidovits, J., (1994). "Properties of Geopolymer Cements." First International Conference on Alkaline Cements and Concretes, pp.131-149.

Duxson, P., Fernández-Jiménez, A., Provis, J. L., Lukey, G. C., Palomo, A., Van Deventer, J. S J, (2007). "Geopolymer technology: The current state of the art." Journal of Materials Science, 42(9), pp.29172933.

Duxson, P., Provis, J. L., Lukey, G. C., Van Deventer, J. S J., (2007). "The role of inorganic polymer technology in the development of "green concrete." Cement and Concrete Research, 37(12), pp.15901597.

Fernández-Jiménez, A. \& Palomo, A., (2003). "Characterisation of fly ashes. Potential reactivity as alkaline cements." Fuel, 82(18), pp.2259-2265.

Hardjito, D., Wallah, S. E., Sumajouw, D. M J., Rangan, B. V., (2004). "On the development of fly ashbased geopolymer concrete." ACI Materials Journal, 101(6), pp.467-472.

Hasanbeigi, A., Menke, C. \& Price, L., (2010). "The CO2 abatement cost curve for the Thailand cement industry." Journal of Cleaner Production, 18(15), pp.1509-1518.

van Jaarsveld, J.G.S. \& van Deventer, J.S.J., (2004). "The potential use of geopolymeric materials to immobilize toxic metals: Part I. theory and application." Minerals Engineering, 10(7), pp.201-251.

Khale, D. \& Chaudhary, R., (2007). "Mechanism of geopolymerization and factors influencing its development: A review." Journal of Materials Science, 42(3), pp.729-746.

Lloyd, N.A. \& Rangan, B. V., (2010). "Geopolymer Concrete with Fly Ash." Second International Conference on Sustainable Construction Materials and Technologies, (January).

Lura, P., Couch, O., Jensen, J., O., M., Weiss, J., (2009). "Early-age acoustic emission measurements in hydrating cement paste: Evidence for cavitation during solidification due to self-desiccation." Cement and Concrete Research, 39(10), pp.861-867.

Pacheco-Torgal, F., Castro-Gomes, J. \& Jalali, S., (2008). "Alkali-activated binders: A review. Part 1. Historical background, terminology, reaction mechanisms and hydration products." Construction and Building Materials, 22(7), pp.1305-1314.

Palomo, A., Grutzeck, M.W. \& Blanco, M.T., (1999). "Alkali-activated fly ashes: A cement for the future.” Cement and Concrete Research, 29(8), pp.1323-1329.

Pazdera, L., Topolar, L., Korenska, M., Smutny, J., Bilek, V., (2014.) “Advanced Analysis of Acoustic Emission Parameters during the Concrete Hardening for Long Time." 11th European Conference on Non-Destructive Testing, (Ecndt).

Sayers, C.M. and Dahlin, A., (1993). "Propagation of ultrasound through hydrating cement pastes at early times." Advanced Cement Based Materials, 1(1), pp.12-21.

Silva, P. De, Sagoe-Crenstil, K. \& Sirivivatnanon, V., (2007). "Kinetics of geopolymerization: Role of A12O3 and SiO2." Cement and Concrete Research, 37(4), pp.512-518.

Sumajouw, D.M.J. et al., (2007). "Fly ash-based geopolymer concrete: Study of slender reinforced columns." Journal of Materials Science, 42(9), pp.3124-3130.

Wallah, S.E., (2011). "Creep Behaviour of Fly Ash-Based Geopolymer Concrete." Civil Engineering, 12(2), pp.73-78.

Wallah, S.E., (2000). "Drying Shrinkage of Heat-Cured Fly Ash-Based Geopolymer Concrete." CCSE journal, 3(12), pp.14-21. 